\title{
Correction to: Price and greenness competition between duopoly firms considering consumer premium payments
}

\author{
Yantao Ling ${ }^{1} \cdot$ Jing $\mathrm{Xu}^{1}$ (D) \\ Published online: 16 May 2020 \\ (c) Springer Nature B.V. 2020
}

\section{Correction to: Environment, Development and Sustainability https://doi.org/10.1007/s10668-020-00747-5}

Unfortunately, there is a reference error in this paper. We transposed professor M. Ali Ülkü's last name and first name. We apologize for our mistake.

The incorrect reference "M. Ali, U., \& Hsuan, J. (2017). Towards sustainable consumption and production: Competitive pricing of modular products for green consumers. Journal of Cleaner Production, 142, 4230-4242" has to be corrected.

The correct reference is provided below.

In this paper the reference has been incorrectly cited as "M. Ali and Hsuan (2017)" throughout the paper the correct citation is "Ülkü and Hsuan (2017)".

The sentence "M. Ali and Hsuan (2017) examine the pricing decisions of modular products between two competing firms where the consumer is sensitive to stainability" appearing in second paragraph of the heading "2.1 Pricing and greenness decisions considering WTP" has to be corrected as "Ülkü and Hsuan (2017) examine the pricing decisions of modular products between two competing firms where the consumer is sensitive to sustainability".

\section{Reference}

Ülkü, M. A., \& Hsuan, J. (2017). Towards sustainable consumption and production: Competitive pricing of modular products for green consumers. Journal of Cleaner Production, 142, 4230-4242.

The original article can be found online at https://doi.org/10.1007/s10668-020-00747-5.

Jing $\mathrm{Xu}$

xujing8023@cqu.edu.cn

Yantao Ling

lingyantao@cqu.edu.cn

1 School of Economics and Business Administration, Chongqing University, Chongqing 400030, China 
Publisher's Note Springer Nature remains neutral with regard to jurisdictional claims in published maps and institutional affiliations. 